\title{
Experimental Analysis of Wind Interaction with Olive Grove and the Atmospheric Surface Boundary Layer
}

\author{
M. Jiménez-Portaz ${ }^{1}$, M. Clavero ${ }^{1}$ and M. A. Losada ${ }^{1}$
}

\begin{abstract}
The emblematic olive grove covers $17 \%$ of the South Spain territory. Last years, intensive farming has been developed around its exploitation. This causes many environmental and social problems, ecological interactions and environmental variables are modified, accentuating the climate change effects. The aim of this work is optimize the layout to allow a sustainable agricultural production, adapting the exploitation to the climate change and minimizing alterations over environmental variables. Thus, interaction between the Surface Boundary Layer (SBL) and olive groves has been analyzed experimentally. Wind tunnel reduced-scale tests were carried out for different setups: grid with homogeneous tree models, over a flat surface and over a hill, and simulating different vegetation covers. The same tests were replicated with staggered pattern and heterogeneous tree models. Wind velocity and turbulence kinetic energy profiles were obtained using Hot Wire Anemometry, taking measurements between models and behind them. It has been proved that olive grove spatial layout and the presence or absence of vegetation cover modify the SBL dynamics. Consequently, not only fundamental environmental variables are altered, for example, the moisture flux and the evapotranspiration, but also important variables for human health are modified, as pollen flow dispersion to urban areas.
\end{abstract}

Keywords: Olive grove, environmental management, sustainability, wind tunnel

\section{Introduction}

The emblematic olive grove is an important ecosystem in the Mediterranean area, covering more than $70 \%$ of the World olive fields (Camarsa et al., 2010). This land use is one of the most extended crops in the South of Spain, reaching more than 1.5 million hectares (Guzmán-Álvarez, Gómez, \& Rallo, 2009).

Last years in order to increase the production and the efficiency, new farming methods have been developed, replacing the traditional spatial distribution (heterogeneous and no coetaneous) and promoting coetaneous olive orchards, homogeneous grids and trees placed closely in a hedgerow (Gómez-Calero, 2009). Soils are compacted and chemically treated in some cases to remove vegetation cover, increasing the erosive processes, being one of the main problems in Andalucía (Amate, de Molina, Vanwalleghem, Fernández, \& Gómez, 2013). Moreover, bare soils and the lack of vegetation change evaporation processes and decrease soil water content, which are crucial variables to olive crop development and its management (Arampatzis et al., 2018).

According to this problem, natural resources exploitation and agriculture sustainability are important society challenges, from an economic, financial, technical, and environmental point of view (Rocamora-Montiel, Glenk, \& Colombo, 2014). It is required to apply the term of sustainability to the agriculture, including some new and innovative practices of management, by means of close collaboration between 
researchers, farmers, politicians, etc.

Thus, it is necessary to find an optimal spatial layout, to allow a sustainable and efficient agricultural production adapted to the climate change, minimizing environmental and human health impacts. In this regard, ecosystems have to be studied in a comprehensive way, taking into account the Atmosphere - environmental variables interactions, and the alterations over the terrain and the whole ecosystem, depending on crop type.

Empiric models have been developed in order to obtain, at local spatial-temporal level, the relationship between different crops (olive grove and vineyard) and climatological scenarios (Moriondo et al., 2015). Other studies use ecohydrological and climatological models to relate the olive trees growth with soil moisture levels (Viola, Caracciolo, Pumo, \& Noto, 2013). Olive fields in the South Spain are located in arid or semi-arid areas, under extreme climatological conditions; in these scenarios, potential erosion and pollen dispersion are good indicators to evaluate and manage this ecosystem (LópezPintor, Salas, \& Rescia, 2018). In these study areas, the influence of vegetation cover on the CO2 exchange and others environmental variables have been studied using the eddy covariance technique (Chamizo et al., 2017) .

Interaction between soil, vegetation and the atmosphere in hydraulic limited ecosystems, as the Andalusian crops, has to be analyzed to study plants development, its spatialtemporal evolution (Baudena, D'Andrea, \& Provenzale, 2008) and alterations due to external disturbances. However, this is a complex and unstable system, difficult to be studied in a full scale, being necessary the use of tools as wind tunnels, traditionally used in aerodynamics and architecture fields. The application of Atmospheric Boundary Layer Wind Tunnels to environmental purposes and small scale analysis of forests is increasing (Gromke, 2018). Wind tunnel tests have been carried out to control wind erosion and eolian sediments transport using plants (Liu, Zheng, Cheng, \& Zou, 2018), for example, to study pollen dispersion of soy crops (Yoshimura, 2011).

The aim of this work is to study the wind flow and the main SBL variables, as wind velocity and turbulence, around grid olive grove over flat terrain inside an Atmospheric Boundary Layer Wind Tunnel. In this document, differences between empty wind tunnel measurements and grid olive grove over flat terrain measurements are analyzed; it is organized as follow: first of all, a brief introduction and justification, section 2 describes the set-up inside the wind tunnel and the methodology, section 3 shows graphs and results derived from experimental tests and, finally, section 4 summarizes the main conclusions.

\section{Set Up and Methodology}

Wind Tunnel tests were performed in the Atmospheric Boundary Layer Wind Tunnel of the Fluid Dynamics Laboratory from the Andalusian Institute for Earth System Research (IISTA, University of Granada). The tunnel has a plan length of 40 meters with a test section of $2.15 \times 1.80$ meters and 15 meters of length. First of all, in order to calibrate the test section, empty wind tunnel measurements were carried out (Jiménez-Portaz, M., 2019), measuring the points of interest in this work, represented over the wind tunnel draft in Figure 1. 

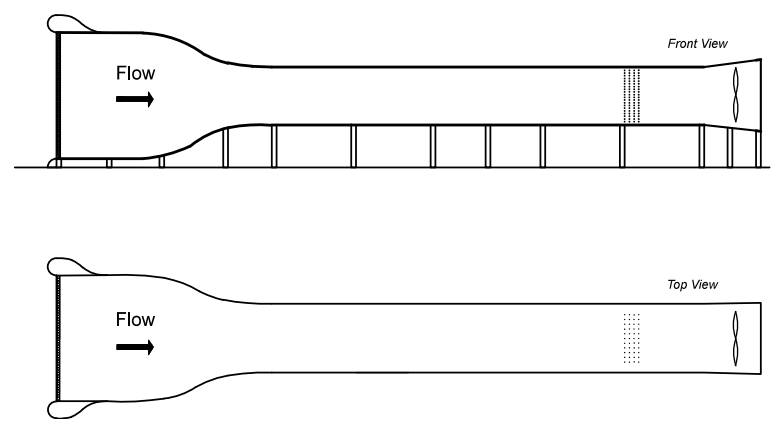

Figure 1. Wind Tunnel draft with measuring points.

The reduced scaled models were olive trees with a scale factor of 1:50. Figure 2 depicts the experimental set-up and Figure 3 shows 2 images of the configuration and the models tested in this work. Twenty-two vertical profiles were measured up to 1 meter high, 6 profiles centered and 8 profiles in the right and lefts sides. The distance between profiles was th (tree height) and 2 th, where th is the tree height $(9 \mathrm{~cm})$. And the distance between measuring planes was 2.5th to allow measurements between models inside the olive field. Each profile consisted of 12 points, wind speed was recorded for each point with a sampling frequency of $1 \mathrm{kHz}$ during 131 seconds using Cross Hot Wire Anemometry to record vertical and longitudinal vector components. The system used was a TSI Inc. IFA300 and data acquisition was conducted using ThermalPro software.

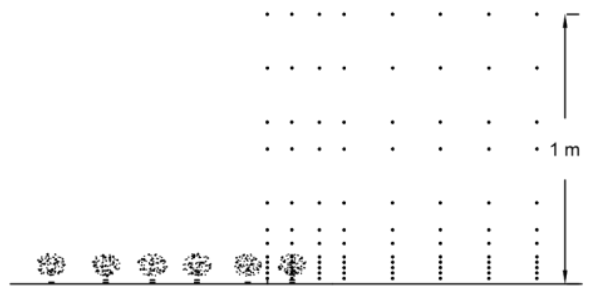

Figure 2. Experimental set-up 
Mean Wind Velocity (Um), Turbulence Intensity (IT), Kinematic Turbulence Energy (TKE) and Reynold's number were selected as main variables of interest, and calculated from experimental data.

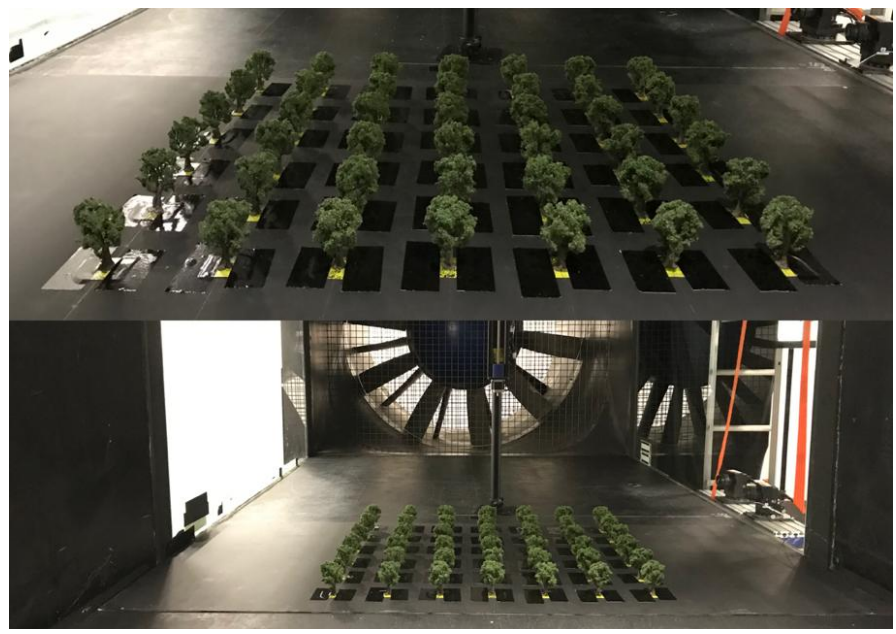

Figure 3. Placement of grid olive grove over flat terrain inside the IISTA Atmospheric Boundary Layer Wind Tunnel.

\section{Results}

Empty wind tunnel profiles and olive grove profiles were obtained at the same spatial locations inside the test section and the same vertical distances between points (Figures 1 and 2). Dimensionless variables above mentioned are graphically represented for each simulation. Figures 4 and 5 show mean wind velocity, turbulence intensity and turbulence kinematic energy obtained for the empty wind tunnel case.
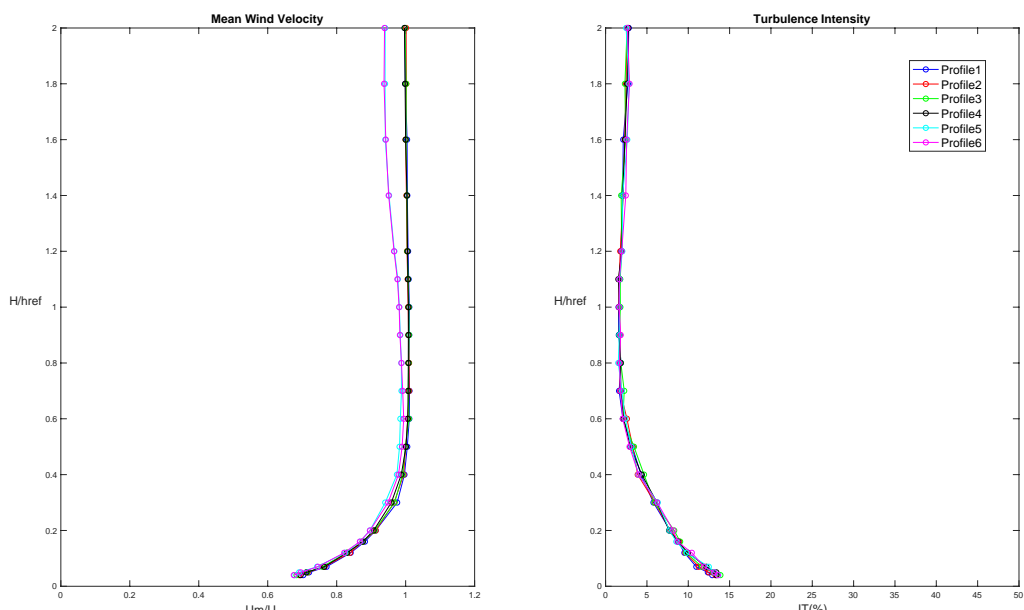

Figure 4. Mean wind velocity and Turbulence intensity for empty wind tunnel. 


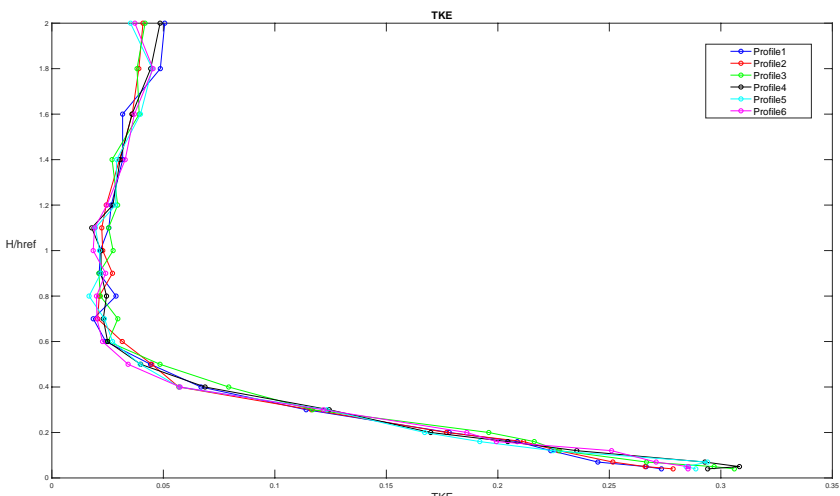

Figure 5. Turbulent kinematic energy for empty wind tunnel.

Figures 6 and 7 show the variables described before for the simulated grid olive grove over flat terrain without vegetation cover.
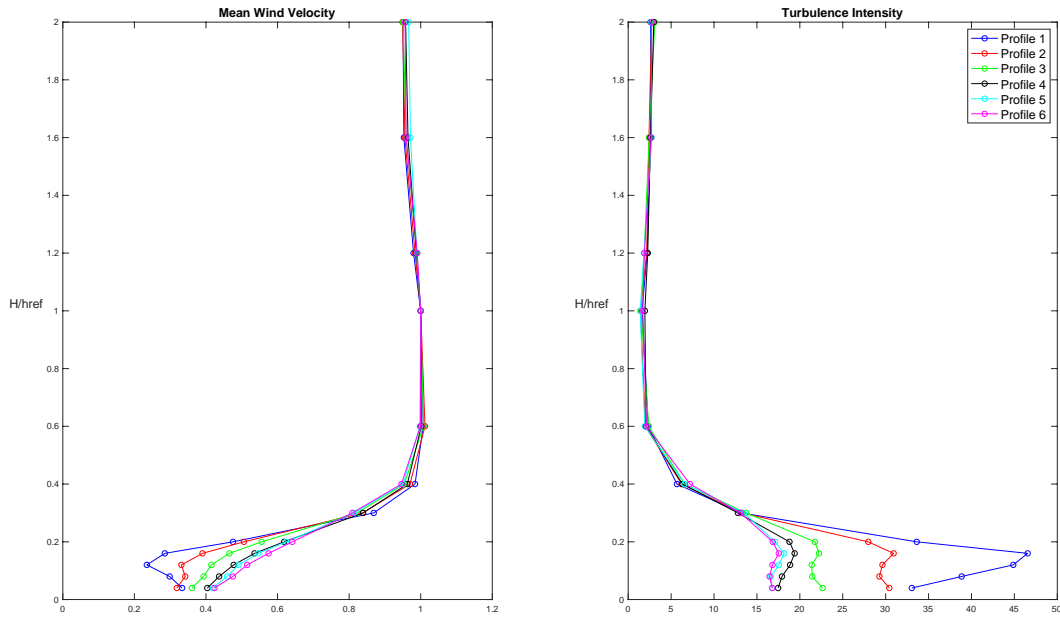

Figure 6. Mean wind velocity and turbulence intensity for grid olive grove over flat terrain.

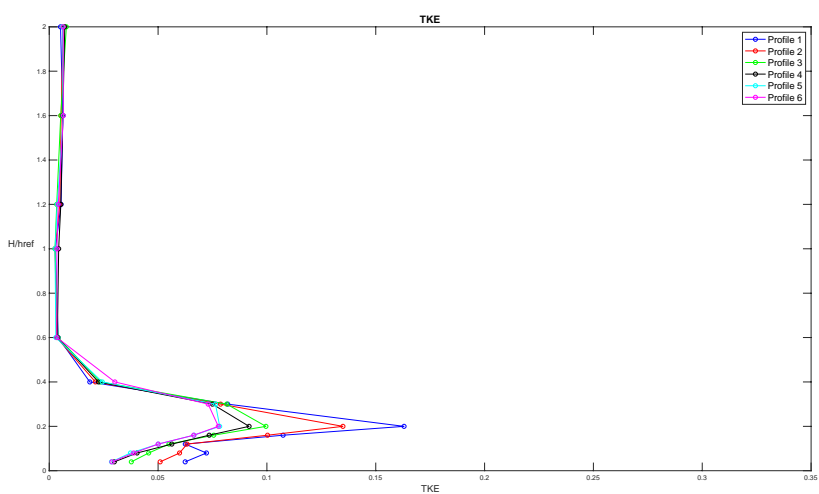

Figure 7. Turbulence Kinematic Energy for grid olive grove over flat terrain. 
Comparing both experiments, many differences are observed: olive grove measurement results show a wind velocity decrease and a turbulence intensity increase, this one is bigger behind the central row of trees. Less energy dissipation is noticed in TKE graph in the vertical profile, however, from 3 th height the profile is more homogeneous. There is greater wind velocity between trees and less turbulence intensity. About 3 th height, the flow becomes uniform in the vertical and about 6 th downwind (from the model) the wind flow is homogenous too.

\section{Discussion and Conclusions}

The aim of this research study is the analysis of the wind flow around olive grove configurations, according to traditional and new crops from the South Spain and compare the results with empty tunnel measurements under the same conditions.

Wind tunnel tests were carried out with olive trees models at 1:50 scale. As the ratio between the cross occupied area by models and the total wind tunnel cross area is smaller than 5\% (CNR, 2008), the blockage effect is negligible. Measurements were taking until a 11 th height above the model, in this regard, data density is representative and higher enough to characterize the area of interest.

The Reynold's number takes values between $8.3^{*} 10^{3}$ and $1.6^{*} 10^{4}$, thus, according to (Simiu, Letchford, Isyumov, Chowdhury, \& Yeo, 2013), these values are higher enough to minimize local viscosity effects. Downwind direction Reynold's number increases for tree height measurements (Figure 8), but its values are constant for SBL top height $(11 t h)$.

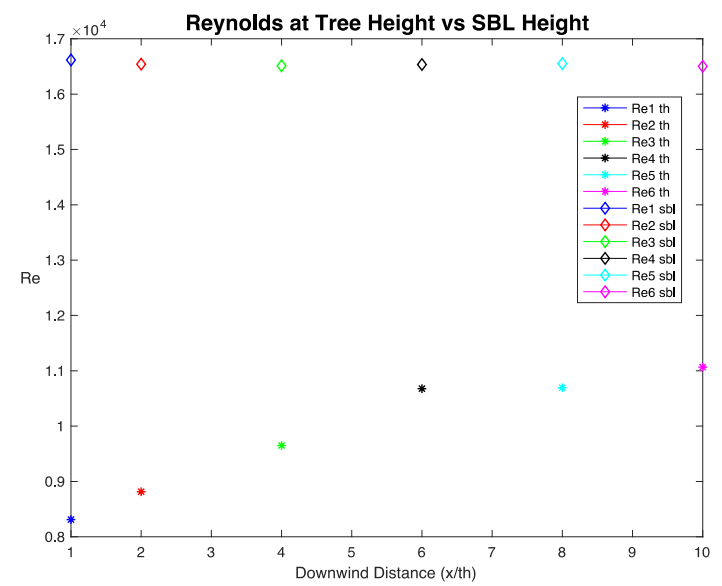

Figure 8. Reynold's number for olive grove calculated at tree height and top SBL height.

Taking into account that rigid models were used to simulate the olive field, it is expected a turbulence distortion due to its inherent rigidity.

Finally, comparing measurements with and without models, it may be concluded that wind tunnel tests allow to study wind flow changes due to the interaction between ecosystems, as an olive grove, and the SBL. At a distance of 3 th in the vertical and 6 th downwind, the flow becomes uniform and the olive field roughness is damped. 


\section{Acknowledgements}

This research was funded by the project "Estudio Experimental de la interacción Atmósfera - Ecosistema Olivar: aplicación al estudio de la dispersión de polen y la sostenibilidad ambiental" from the Program "Proyectos de Investigación Precompetitivos para Jóvenes Investigadores” from the University of Granada.

\section{References}

Amate, J. I., de Molina, M. G., Vanwalleghem, T., Fernández, D. S., \& Gómez, J. A. (2013). Erosion in the mediterranean: The case of olive groves in the south of spain (1752-2000). Environmental History, 18(2), 360-382. doi:10.1093/envhis/emt001

Arampatzis, G., Hatzigiannakis, E., Pisinaras, V., Kourgialas, N., Psarras, G., Kinigopoulou, V., et al. (2018). Soil water content and olive tree yield responses to soil management, irrigation, and precipitation in a hilly mediterranean area. Journal of Water and Climate Change, 9(4), 672-678. doi:10.2166/wcc.2018.224

Baudena, M., D'Andrea, F., \& Provenzale, A. (2008). A model for soil-vegetation-atmosphere interactions in water-limited ecosystems. Water Resources Research, 44(12) doi:10.1029/2008WR007172

Camarsa, G., Gardner, S., Jones, W., Eldridge, J., Hudson, T., Thorpe, E., et al. (2010). Good practice in improving environmental performance in the olive oil sector. Office for Official Publications of the European Union, Luxembourg,

Chamizo, S., Serrano-Ortiz, P., López-Ballesteros, A., Sánchez-Cañete, E. P., Vicente-Vicente, J. L., \& Kowalski, A. S. (2017). Net ecosystem CO2 exchange in an irrigated olive orchard of SE spain: Influence of weed cover. Agriculture, Ecosystems \& Environment, 239, 51-64.

CNR. (2008). Guide for the assessment of wind actions and effects on structures-CNR-DT 207/2008.

Gómez-Calero, J. A. (2009). Sostenibilidad de la producción de olivar en andalucía

Gromke, C. (2018). Wind tunnel model of the forest and its reynolds number sensitivity. Journal of Wind Engineering and Industrial Aerodynamics, 175, 53-64. doi:10.1016/j.jweia.2018.01.036

Guzmán-Álvarez, J., Gómez, J. A., \& Rallo, L. (2009). El olivar en andalucía: Lecciones para el futura de un cultivo milenario. (pp. 7-20)

Jiménez-Portaz, M., et al. (2019). Flow analysis and calibration: comparison between an open-circuit and a close-circuit wind tunnel. (In submit)

Liu, C., Zheng, Z., Cheng, H., \& Zou, X. (2018). Airflow around single and multiple plants. Agricultural and Forest Meteorology, 252, 27-38. doi:10.1016/j.agrformet.2018.01.009

López-Pintor, A., Salas, E., \& Rescia, A. (2018). Assessment of agri-environmental externalities in spanish socio-ecological landscapes of olive groves. Sustainability, 10(8), 2640.

Moriondo, M., Ferrise, R., Trombi, G., Brilli, L., Dibari, C., \& Bindi, M. (2015). Modelling olive trees and grapevines in a changing climate. Environmental Modelling \& Software, 72, 387-401. doi:10.1016/j.envsoft.2014.12.016

Rocamora-Montiel, B., Glenk, K., \& Colombo, S. (2014). Territorial management contracts as a tool to enhance the sustainability of sloping and mountainous olive orchards: Evidence from a case study in southern spain. Land use Policy, 41, 313-324.

Simiu, E., Letchford, C., Isyumov, N., Chowdhury, A. G., \& Yeo, D. (2013). Assessment of ASCE 7-10 standard methods for determining wind loads. Journal of Structural Engineering, 139(11), 2044-2047. doi:10.1061/(ASCE)ST.1943-541X.0000771

Viola, F., Caracciolo, D., Pumo, D., \& Noto, L. V. (2013). Olive yield and future climate forcings. Procedia Environmental Sciences, 19, 132-138.

Yoshimura, Y. (2011). Wind tunnel and field assessment of pollen dispersal in soybean glycine max (L.) merr.]. Journal of Plant Research, 124(1), 109-114. doi:10.1007/s10265-010-0357-y 